\title{
Aportacions del Vocabulario de Enguera y la Canal de Navarrés als estudis del lèxic valencià $i$ xurro
}

\author{
[Contributions of the Vocabulario de Enguera y la Canal de \\ Navarrés to the study of Valencian and churro lexicon]
}

\author{
Joseph Gulsoy \\ University of Toronto \\ jgulsoy@sympatico.ca
}

Resum: El present article és un tast del Vocabulario de Enguera y la Canal de Navarrés, actualment en fase d'elaboració molt avançada. S'ofereix, ara, un exemple d'aquest vocabulari, que no sols aportada dades per al coneixement dels parlars xurros valencians, sinó també per al lèxic del valencià.

PARAUlES CLAU: parlars xurros, valencià, lèxic, vocabulari

Авstract: This article is a tasting of the Vocabulario de Enguera y la Canal de Navarrés, which is currently under development. An example of this vocabulary is now offered, which not only provided data for the knowledge of the Valencian churros dialects, but also for the Valencian lexicon.

KEYwORDS: churros dialects, Valencian, lexicon, vocabulary

Recepció: I6/06/2017. Acceptació: OI/IO/20I7. Publicació: I 5/I2/20I7

REVISTA VALENCIANA DE FILOLOGIA / I (20I7) p. I 83-I98 / ISSN 0556-705X / DOI I0.28939/RVF.VIII.26 
1. Es tracta del vocabulari del parlar xurro d'Énguera i dels pobles d'Anna, Xella, Bolbait, Navarrés, Quesa i Bicorb. El lèxic d'aquesta zona, de base castellanoaragonesa, comprèn romanalles de l'aragonès, gran nombre de mots d'origen valencià i elements del castellà antic i dialectal. Té molt en comú amb d'altres parlars xurros, com ara els dels Serrans, de l'Alt Millars, de Sogorb i del Racó d'Ademús, i gran afinitat amb el lèxic de Requena-Utiel i Albacete, i també amb el del dialecte de Múrcia i parlars relacionats.

Els materials del Vocabulario foren recollits durant el període 19651975. Al principi, era un projecte de col-laboració amb el distingit filòleg Manuel Sanchis Guarner. Ell estava encarregat de l'estudi lingüístic preliminar. L'any 1976 ja estàvem pensant d'enllestir el Vocabulario per a la publicació, però em calgué ajornar el projecte indefinidament per raons de compromisos professionals. ${ }^{1}$ Finalment, després de quaranta anys, al novembre de 2013, em va ser possible iniciar-ne la redacció definitiva. A hores d'ara hem arribat a la lletra R i preveig completar el treball dins d'un any. ${ }^{2}$

2. Durant el període de 1965-1975 teníem reunits més de 6.000 vocables, en gran part ben documentats amb exemples de llur ús del parlar viu i de fonts escrites. De bon principi, vam tenir la bona fortuna de comptar amb un rudimentari «Vocabulario enguerino» (en manuscrit), compilat per Jaime Barberán Juan (1915-1989) als anys de jove (1934-1935), quan el dialecte tenia notable vitalitat. Aquest «Vocabulario» tenia prop de 1.500 entrades. Em plau afegir que el senyor Jaime, que era l'alcalde de la vila d'Énguera en aquells anys, va continuar contribuint a la nostra compilació amb llistes de vocables i expressions llavors i després.

1 Per aquells anys tenia publicat en relació amb el tema: «L'origen del parlar d'Énguera i la Canal de Navarrés", Estudis Romànics, XII, 1963-1968, 317-338 (reproduït en: Joseph Gulsoy, Estudis de filologia valenciana, "Col-lecció Honoris Causa", València, Universitat de València, 2001, p. 231-252.

2 Tenim publicat sobre el tema: «Los rasgos más notables del habla de Enguera y de Anna», $I$. Jornada de parlars de base castellano-aragonesa, València, Denes, 2010, 205-218; "La elaboración del Vocabulario de Enguera i La Canal de Navarrés», II. Jornades sobre els parlars valencians de base castellanoaragonesa, Enguera, 2013, València, Denes, 2014, 27-40.

REVISTA VALENCIANA DE FILOLOGIA / I (20I7) p. I83-I99

JOSEPH GULSOY

Aportacions del 'Vocabulario de Enguera y la Canal de Navarrés' / i 84 
La replega del parlar viu es va efectuar durant 1965-1975, amb visites anuals a la zona, treballant amb informants d'edat madura, ben coneixedors del dialecte. Era costum reunir-se al bar amb un grup de tres o quatre individus que solia incloure llauradors, algun jornaler, el guàrdia municipal i el mestre d'escola jubilat. A més, Sanchis Guarner, gran dialectòleg, va omplir, durant el març de 1968, dos quaderns de l'Atlas Lingüístico de la Península Ibérica (ALPI) a Enguera, Anna, Xella, Bolbait i Navarrés. És sabut que ell era part de l'equip de dos que havia fet, l'any 1947, l'enquestes de l'ALPI a Anna.

Una part molt important de la compilació procedia de les fonts de la literatura local enguerina, ben vibrant, constant de sainets, romances, historietes, recompte de festes i de costums, narracions de passades jocoses, records del passat enyorat..., escrits d'autors com Jaime Barberán, amants de la cultura i el parlar del seu poble. Els treballs en qüestió foren publicats en dos òrgans periòdics: 1) A Nuestros Jóvenes (Ns. Jovs.), Circular mensual del Centro Parroquial de los Jóvenes de la Acción Católica, núms. 1-159 (juliol 1944 - agost 1958; 2) Enguera (Eng.), Revista anual publicada per l'Ayuntamiento de la Villa de Enguera des de 1959. Els vocables d'aquestes fonts foren reproduits en citacions adequades en la mesura que eren testimonis il.lustratius de significats.

Els següents treballs, que apareixen més citats en les entrades del Vocabulario, es poden considerar els clàssics de la literatura local enguerina: Los últimos castizos, (Eng., 1966, 175-181), peça teatral en vers, d'un acte, escrita en 1927 per Manuel Albiñana Sanz (1896-1970); Pa sainetes Engra u aquí no ha pasáu ná (Ns. Jovs., 87, 1951, 12 - 14), de Jaime Barberán; El viaje a Madrit (Eng., 1962, 59-61) de José Ciges Pérez (1904-1974); Día de quintas (Eng., 1963, 92-95) d'Emilio Granero - J. Ciges.

Són igualment molt citats els textos de la sèrie Itinerario lírico por las calles de Enguera, de Miguel Ciges Pérez (1901-1989), publicats a la revista Enguera. 1960, 1961, 1963, 1965, 1966, 1967, 1969, 1970-71, 1973. El Sr. Miguel Pérez (1901-1989), magistrat, «amb domicili a València», hi recompta: "Yo no hablo de hoy, hablo de hace más de cincuenta años [cuando yo era muchacho], escribo mis impresiones, mis recuerdos de estas calles, también

REVISTA VALENCIANA DE FILOLOGIA / I (20I7) p. I83-I99 JOSEPH GULSOY Aportacions del 'Vocabulario de Enguera y la Canal de Navarrés' / I 85 
mis nostalgias», $\mathrm{i}$ anomena molts objectes i expressa molts sentiments amb vocables enguerins. ${ }^{3}$

3. Durant l'interval de 1976 i 2013 es publiquen vocabularis de sengles pobles de la zona. Emili Martí, valencià, professor ensenyant a Xella i domiciliat a Anna, i Salvador Aparicio, funcionari de l'Ajuntament d'Anna, el meu excellent i excepcional informant, publiquen en col-laboració: El léxico de Anna (Anna, 1989), patrocinat per l'Ajuntament d'Anna. L'any 2005 se'n fa una edició ampliada amb el títol El hablar de Anna (Canals, la Costera) (Anna: Martí-Aparicio)

Inspirat per ells, publiquen J. A. García López, Así charramos. El léxico de Quesa (Quesa, 1996) (Quesa: GLópez) i J. Luis Ponce Palop, Ensayo sobre la filología chellina. El habla de Chella (Alaquàs, 2008); l'edició renovada, ampliada 2013 (Chella: Palop)

I l'enguerí Matías Aparicio Simón, professor jubilat i autor de sainets, publica: Palabras enguerinas, vol. I (Sierra Fundación de la CV., 2012, 138 p.), vol. II, 2015, 181 p.); (= Eng.: Mat. Aparicio). L'autor explica com havia format aquest treball de gran valor: «Nosotros, a través de la página de Internet De parla enguerina hemos ido ofreciendo mensualmente una serie de palabras y expresiones enguerinas extraídas tanto de las fuentes escritas que poseemos como de las conversaciones diarias de nuestros paisanos. Ahora os lo presentamos en forma de libro» (I, p. 11).

Últimament, es va afegir a la llista la compilació de més de dos-centes pàgines, ben valuosa, Parla enguerina, de la filòloga M. Amparo Garrigós Cerdán. Apareix com a part del llibre Enguera. Parla, flora, toponimia, Amigos de Enguera. Sociedad Cultural, 2017.

3 Jo solia visitar-lo a la seua casa a València demanant-li aclariments sobre els mots usats per ell, i ell s'hi refereix un cop a l'article d'Enguera (1969-1970): «Como todo esto lo lee, lo repasa y hasta después me pide cuentas nuestro querido amigo Don José Gulsoy, nuestro enguerino-canadiense, voy a transcribirle una conversación de la época con motivo de una representación... » (p. 204).

REVISTA VALENCIANA DE FILOLOGIA / I (20I7) p. I83-I99 JOSEPH GULSOY

Aportacions del 'Vocabulario de Enguera y la Canal de Navarrés' / I 86 
Amb aquestes noves publicacions es van enriquir, en gran mesura, els nostres materials amb mots o sentits no registrats abans, i també amb abundants exemples que il.lustren els sentits del mots, usats pels autors mateixos en el quefer diari o oïts per ells en les converses d'altres.

4. També va haver-hi novetats en l'àmbit dels parlars xurros relacionats i d'altres afiliats. Pels anys de 1970, dels altres parlars xurros es coneixia només el treball de Vicente Llatas, El habla del Villar del Arzobispo y su comarca, Institución Alfonso el Magnánimo, Valencia, 1959.

A l'època posterior, va haver-hi addicions importants. La filòloga Natividad Nebot Calpe va estudiar el lèxic de l'Alt Millars i l'Alt Palància en una sèrie d'articles publicats en Archivo de Filologia Aragonesa (AFA), 26-27, 1980, 193-223; 28-29, 1981, 57-81; 44-45,1990, 95-180; 50,1994, 155-195 (Nebot, AFA; tenim, a més, Isabel Alba, El habla de Ludiente, Castelló de la Plana, Diputació de Castelló, 1986 (I. Alba). J. Enrique Gargallo, Habla y cultura popular en el Rincón de Ademuz, Madrid, 2003, Anejo RFE (Gargallo); A. Briz, El parlar de la comarca de Requena-Utiel, València, Generalitat Valenciana, 1984 (Briz)

5. Respecte al tractament del lèxic, volem assenyalar els següents punts:

a) En les entrades, les definicions del sentit principal del mot i els de les accepcions s'il-lustren amb citacions d'exemples del parlar viu i de les fonts escrites. A més, quan són disponibles, indiquem, a manera de suport, les correspondències en d'altres parlars xurros, com ara el dels Serrans, l'Alt Millars, Segorbe, el Racó d'Ademús, i dels parlars de les regions properes, o siga, de la zona manxega i Múrcia i Andalusia.

$b$ ) Com és normal en un vocabulari de base xurra, hi indiquem l'origen de provinença dels mots: aragonès, valencià o castellà dialectal o antic. Quan escau, s'hi fa constar si els mots d'aquests orígens han tret o han assumit nous brots en llur nou ambient

c) En més d'un cas va ser problemàtic indicar el mot valencià del qual procedien les formes de la nostra zona, puix que ja no tenen ús a la regió d'ori-

REVISTA VALENCIANA DE FILOLOGIA / I (20I7) p. I83-I99 JOSEPH GULSOY Aportacions del 'Vocabulario de Enguera y la Canal de Navarrés' / I 87 
gen —normalment és propera- $\mathrm{i}$ fins eren desconeguts en valencià en general. En tal casos ens calgué fer una indagació lèxica extensa.

d) En un bon nombre de casos fou necessari i desitjable tenir a la vista l'origen etimològic del mot i inclús el desplegament semàntic per a establir-ne el sentit amb exactitud. En una sèrie de casos això no va ser possible, perquè l'etimologia del mot no restava aclarida del tot o bé no ben explicada. En tals casos, vam mamprendre l'estudi etimològic dels mots en qüestió amb la deguda atenció com a part integral dels articles del Vocabulario. I em complau reportar que en el cas d'alguns vocables d'origen valencià o aragonesocastellà amb un sentit particular a la nostra zona resultaven ser la dada bàsica, la dada clau per a la resolució d'alguns problemes etimològics.

En definitiva, podem dir que l'aportació del Vocabulario als estudis lèxics del valencià i del castellà dialectal, als estudis xurros, ha estat notable. A continuació reproduïm el text sencer de les entrades de nou vocables i expressions per oferir una idea aproximada d'aquesta aportació.

6. Els mots i expressions que oferim ací són: madrilla, manta, mantáfula, merdancho, noguera, novalido, novichero, palitroc, ni perpenta, pliego (llevar a), i els reproduïm tal com apareixeran al esmentat Diccionario: ${ }^{4}$

4 Títulos abreviados:

DECat: Coromines, Joan. Diccionari etimologic i complementari de la llengua catalana, I-X. Barcelona, Curial, 1983-2001.

Dicc. Acad.: Real Academia Española. Diccionario de la lengua española, 19 ed., Madrid, 1970.

DCECH: Coromines, Joan; PASCUAL, J. A. Diccionario crítico etimológico castellano e hispanico, 2a ed., Madrid, Gredos, 1987-1991.

DCVB: Alcover, Antoni; Moll, Francesc de B., Sanchis Guarner, Manuel. Diccionari català-valencià-balear, Palma de Mallorca, 1930-1962.

Escrig: Escrig, J. Diccionario valenciano - castellano, València, 1851.

Martí Gadea: Martí I GadeA, J. Novíssimo diccionario general valenciano -castellano, València, 1891. Borao: Borao, Jerónimo. Diccionario de voces aragoneses, 2a ed., Saragossa, 1908.

PAsso: Pardo Asso, José. Nuevo diccionario etimológico aragonés, Saragossa, 1938.

Andolz: Andolz, Rafael. Diccionario aragonés. Aragonés-castellano. Castellano-aragonés. 2a ed., Saragossa, 1984.

Rohlfs: Rohlfs, G.. Diccionario dialectal del Pirineo aragonés. Saragossa, 1985.

GSoriano: García Soriano, J. Vocabulario del dialecto murciano, Madrid, 1932.

REVISTA VALENCIANA DE FILOLOGIA / I (20I7) p. I83-I99

JOSEPH GULSOY

Aportacions del 'Vocabulario de Enguera y la Canal de Navarrés' / i 88 
(a) Madrilla. Boga, pez de río (Eng, Chella, Bolb, Nav), bòga (Anna). El naturalista valenciano Cavanilles en su visita a nuestra zona (ca.1790), refiriéndose a una marjal ('pantano') cerca de Navarrés, llamada el Pescado, dice: «En éste no hay barbo alguno, sino solamente unos pececillos llamados madrilla, que salen en abundancia en marzo y abril; hallándose en las otras marjales gran cantidad así de madrilla como de barbos» (Observaciones..., II, 1797, p. 38). J. Guillén (El habla de Oribuela): madrillica «nombre con que se designa a los barbos pequeños» (p. 285).

Cf. Dicc. Acad. de madrilla como vocablo de Aragón; y de hecho aparece abundantemente en fuentes léxicas aragonesas: Borao y PAsso lo tren junto con madrillera 'aparejo o red para pescar madrillas'; Rohlfs localiza madrilla en Ansó, Hecho y Huesca (Alto Aragón) y Andolz en Salvatierra y Puebla de Híjar; se da también en Navarra (Iribarren) y en el dominio catalán: Tortosa y en valenciano $(D C V B)$. Por otra parte, en Murcia aparece junto con la variante madrija (GSoriano), y ésta es la forma en Segorbe (Torres Fornés) y Rincón de Ademuz (Gargallo). Notemos: madrilla proviene del lat. vg. matrícŭla (lat. matrícŭlus) (DCECH III, 754b31), con la solución normal del grupo $-c^{\prime} l->[K]$ (-1l-) en aragonés y catalán. La variante madrija refleja la solución castellana de $-c^{\prime} l->[\mathrm{lj}]>[\check{z}]>[\mathrm{x}](\mathrm{j}) ;$ cf. ocŭlu > ojo); y puede ser como cree Gargallo (p. 59) un caso de castellanización del vocablo en las hablas apuntadas.

(b) Manta. Manta // 2. Manta de tela que se tiende debajo del olivo para recoger las aceitunas que caen al varearlas (Quesa) // 3. Manta jerga: trozo de tela o albarda de aparejar bestias (GLópez) // 4. Holgazán, vago // 5. Sembrar a manta: sembrar los cereales a voleo, es decir, echando los granos a puñados esparciéndolos sobre la tierra // 6. loc. adv. a manta: en gran cantidad, en abundancia (Eng, Anna, Bolb): «Llevo un cabazo de monas, / dosetas de chuchurrutas / con zucre a manta y pansetas» (Cancioneta de la PP, Pascua 1957); «Aguaño hay caracoles a manta» (Martí-Aparicio)

Cf. acep. 6: a manta 'molt, en abundania' es popular en catalán y valenciano, y tb. en Aragón y Navarra (DCECH, DCVB, PAsso, Andolz, Iribarren); en castellano: a manta de Dio; Coromines-Pascual piensan que quizá proceda

REVISTA VALENCIANA DE FILOLOGIA / I (20I7) p. I83-I99 JOSEPH GULSOY Aportacions del 'Vocabulario de Enguera y la Canal de Navarrés' / I 89 
de manta de palos, de azotes, que el Dicc. de Autoridades (1726-1739) documenta en un escrito de 169 (DCECH III, 829b42ss.); parece que, pero, que procedería más bien de un contexto como una manta de olivas o mantas de olivas resultantes de la acción descrita en acep. 2. En cuanto a sembrar a manta (los cereales), la idea de manta vendría del hecho de cubrir los simientes la tierra a manera de una manta; cf. Dicc. Acad. manta \# 10: a manta: «Dícese del modo de regar el terreno cubriéndolo en una capa de agua» (s.v.)

Referente a manta 'holgazán, vago', notemos que se documenta bien en valenciano desde una obra de Carles Ros, 1758 (Martí Mestre, Dicc. val. hist. col., s.v.); interesa: ser una manta mojada (and.) 'no servir, no tener arreste de voluntad para nada (AVenceslada), y la locución val. ser una manta banyá 'ser inútil o no servir para nada' (Martí Gadea, Dicc. val., s.v.)

(c) Mantáfula (var. mantáfulla). Adulteración, fraude (Eng.); «El hombre de las velas / las tiene bien blanquetas / ... de cera virgen / sin mantáfula de ná» (J. López Marín, La cazuela del arroz, Eng., 1968, 63); val. mantàfula

Notemos: val. mantàfula es una de las formas variantes que se dan en el dominio catalán en general; las otras son: matàfula, metàfula, metáfora, metafra, mettafera. Son continuaciones alteradas, predictibles, de la voz metáfora, figura retórica, de origen griego, que habiéndose llegado a tener uso popular en catalán se ha desarrollado en torno la idea semántica de 'falsificación, adulteración' (DECat VI, 777ª 50ss.). Este diccionario reporta el uso de metrafa (< metafra) en el sentido de 'trampa, falsificación' en catalán central, y mettàfera 'barreja, impuresa' en Mallorca y Menorca. El vocablo ya aparece en un escrito de 1515: «Perquè lo mostassaf puga esperimentar si en lo dit vi aurà matàfara o engan» (DCVB, s.v. metàfora). Todo indica que debió de tener el sentido de 'adulteración' ya en el siglo xv.

En valenciano se especializa la forma mantàfula con la variante matàfula. Escrig, Dicc. val.-cast. (1851) trae mantàfula 'engaño solapado o simulado', y Martí Mestre (Dicc. hist. val. collloq.) documenta mantàfula en Rondalla de Rondalles de Lluís Galiana (1769), y matàfula en una obra de 1844-45 (s.v.). Eugeni S. Reig (El valencià de sempre) indica el uso de mantàfula / -fola

REVISTA VALENCIANA DE FILOLOGIA / I (20I7) p. I83-I99 JOSEPH GULSOY

Aportacions del 'Vocabulario de Enguera y la Canal de Navarrés' / I 90 
en escritores de la categoría de Joan Olivares y Enric Valor (p. 486). Interesa agregar que en Enguera se usa también el infinitivo mantafular 'cometer fraude, engañar', que parece ser una innovación local.

(d) Merdancho. Suciedad que sale de una casa o de una fábrica y de los mataderos (Eng.): «Pues en esta calle del Santísimo, tan calada y tan blanca, cuando yo de muchacho pasaba por ella me parecía que de sus arbellones en lugar de merdancho iban a salir armiños» (M. Ciges, Itinerario lírico, Eng., 1963, 100)

Cf. La suciedad que pasa por el albellón incluye en buena parte excremento, y eso sugiere que merdancho sea una formación de merd-. El vocablo aparece en Murcia en la variante merancho y el derivado meranchón con el mismo sentido. García Soriano define merancho: «Lo mismo que landrona. Cauce mayor del avenamiento» (Vocab. del dial. murc., p. 83). Esta forma landrona procede del val. androna, donde significa: "Conducte subterrani per on se'n van les aigües residuals, albelló»(Ferrer Pastor, Dicc. Gen., s.v.). Allí tenemos el esquema semántico: enguerino merdancho 'suciedad que sale de las casas' à murciano merancho 'albellón, conducto que lleva la suciedad a su destino'.

El vocablo no se documenta en castellano; no aparece en el Dicc. Acad. y no está mencionado en el DCECH. Por otra parte, su relación con los topónimos catalanes - nombres de ríos y torrentes- es evidente. Merdanç, antes Merdanço, Merdançà y Merdançó. Son nombres derivados de merd(a) porque solían ser colectores de las inmundicias de los pueblos por los cuales pasaban. Son frecuentes en la toponimia catalana, y se dan también en el territorio occitano y en francés central. Su origen fue estudiado por Coromines en el Onomasticon Cataloniae (V, 257-58).

De la documentación antigua que se da allí deducimos que Merdanç / Merdanço perpetuan el apelativo cat. ant. merdanç(o) 'inmundicias de las casas, derivado de MERDANTIU; Merdançà supone MERDANTI + -ANU (con sufijo adj.), y Merdançó (que tiene correspondencia en Merdançon en la toponimia francesa), de MERDANTI + ONE); cf. murciano me(d)ranchón.

REVISTA VALENCIANA DE FILOLOGIA / I (20I7) p. I83-I99 JOSEPH GULSOY Aportacions del 'Vocabulario de Enguera y la Canal de Navarrés' / I9I 
Así, pues, enguerino merdancho y murciano merancho tienen equivalencia en el cat. ant. merdanço (de MERDANTIU); un resultado con -ancho sólo se puede explicar como solución de -ANTIU en mozárabe, y, con este motivo, recordemos que Murcia y sus alrededores son regiones mozárabes por excelencia.

Notemos que hay un poco de diferencia en las etimologías de Merdanç y Merdançó que damos y las del maestro Coromines, que no tenía a mano el precioso dato que nos proporciona el enguerino merdancho junto con el murciano merancho.

(e) Noguera (var. nuguera) o anoguera. Nogal (Uso general): «Si alguno se sube a un árbol / o va junto a él a pixar, / o si emprende a la noguera / venga a tirarli pedrás» (S. Simón Pérez, Uno pa Sor María, Ns. Jovs., 111, 1953, 17); «En las carpinterías del pueblo no había aparatos mecánicos ... Se trabajaba la madera de la tierra, madera de pino, de carrasca, de noguera, de alionero» (M. Ciges, Itinerario lírico, Eng., 1969, 196); "La anoguera haze anuezes» (Chella); noguera es usual en Alto Mijares (Nebot, AFA 44-45, 1990, 138), Rincón de Ademuz (Gargallo)

Cf. Las dos formas noguera y anoguera se oyen en nuestra zona; la variante anoguera muy probablemente se debe al fenómeno de falsa división: la noguera - l'anoguera. En valenciano alternan: noguer / nouer y (a)noguera / (a) nouera (DECat VI,970b17).

El apelativo noguera proviene de *NŬCARIA; es vocablo eminentemente aragonés; se oye con la var. nuguera en Ansó, Valle de Bielsa, Echo, Eje, Embún, Lanaje, Loarre, Panticosa, Huesca (Rohlfs, Andolz); en la época medieval se documenta en algunos escritos y también en el Fuero de Teruel (DECat VI, 970b17). Este dato es de gran interés para nosotros, ya que el origen aragonés de las hablas churras se relaciona con el aragonés de la zona de Teruel.

(f) Novalido, da. Crecido y bien desarrollado, normalmente con referencia a niños bien desarrollados (Uso general): «[Yo] ha visto tu ñeto y está muy novalido» (Anna); "Ché, hay que ver lo novalido que está la chicona de Encarnita» (Bolb); «El tío Argunzaico lleva a su hijo, vástago muy novalido de diez

REVISTA VALENCIANA DE FILOLOGIA / I (20I7) p. I83-I99 JOSEPH GULSOY

Aportacions del 'Vocabulario de Enguera y la Canal de Navarrés' / I92 
años, a una función del teatro» (Ns. Jovs., 108, 1953, 2); "Nuestro pastor era un gran pastor ... su ganado iba siempre viento en popa; tenía siempre buena paridera; sus corderos eran siempre los más validos de la contorná» (M. Ciges, Itinerario lírico, Eng., 1973, 146); en Quesa noválido,da 'guapo, lleno de vitalidad (García López) // Mat. Aparicio, Palabras enguerinas, II: novalido: «Persona fuerte fisícamente de apariencia y de hechos. Le dicen a uno que ha sido elegido segundo "abanderáu”: “Aprepara el esquilón / que no tendrá San Antón padrino más novalido" » (p. 176); cf. en Albacete: novalio «se dice de personas o cosas que no crecen o están enfermas» (Zamora Vicente, RFE 27, 1943, 251)

Novalido se ha formado del adjetivo castellano novalio 'renuevo, cogollo', por ultracorrección; la forma noválido de Quesa se debe a la tendencia a cambiar la acentuación de llana a esdrújula en quesino; por otro lado, novalio 'que no crece' de Albacete refleja la misma tendencia acentual en novalio y la asociación del vocablo por 'no valer' por consecuencia.

El adj. novalio, por su parte, es un derivado de noval, que pertenece a una familia extensa románica: port. noval, cat. noval, fr. ant. novel, it. novale, procedentes del lat. novale 'tierra nuevamente arado y cultivado'. Notemos: it. novale 'campo lavorato novamente, dopo longo riposo, por una nuova coltura'; cast. noval, según Dicc. Autor. se aplica «a las tierras que se cultivan de nuevo; a los frutos que produce, y a los árboles y plantas»; según Dicc. Norm. Val.: noval adj. i sust. 'que es comença a conrear o que es conrea novament' (un tros de terra) després d'haver-ne tret les males herbes' y novaliu 'noval'.

Novalio se documenta en castellano en el sentido de 'renuevo, cogollo' (1490) (DCECH s.v. nuevo). En arag. 'desarrollado, precoz' (Andolz, recogido en Monzón), y en nuestra zona: 'crecido, bien desarrollado', por una parte, y por otra 'hermoso, lleno de vitalidad'.

El desarrollo semántico es evidente: la idea de tierras que se cultivan de nuevo, después de largo tiempo en barbecho, producen con fuerza renovada frutos bien desarrollados y de muy buena cualidad, se ha dicho de niño bien desarrollado o de muchacha hermosa, de gran vitalidad'.

Llama la atención el gran florecimiento que ha tenido el vocablo en nuestra zona.

REVISTA VALENCIANA DE FILOLOGIA / I (20I7) p. I83-I99 JOSEPH GULSOY Aportacions del 'Vocabulario de Enguera y la Canal de Navarrés' / I93 
(g) Novich. m. f. Lo mismo que novichero 'curioso' (Vocab. eng. de 1934); todavía en uso; Mat. Aparicio (Palabras enguerinas, II) nos da este ejemplo: «¿Qué ande vais? —Por ahora sólo de novich» (p. 159)

Novichear. intr. Curiosear (Eng, Anna, Chella, Bolb, Nav): «La ventanilla por la que mira y ve la calle el tejedor, por la que novichea» (M. Ciges, Itinerario lírico, Eng., 1963, 101); «PEPI. Pos yo quiero novichear tó esto. El que no novichea no s'entera. TÍO MIGUEL. No seas mal educá. ¡Malhacendera! Que siempre me recremas la sangre» (R. Ros Marín, Los pastoretes d'Engra, Ns. Jovs., 66, 1949, 11)

Novichero, ra. Curioso, fisgón (Eng, Chella): «Un hombre que toma el fresco ... los detiene [a los chicos]. —Ché, Pepito, ¿a ver, a ver? Y el chiquillo, todo orgulloso, levanta el farol ante el rostro del novichero" (Mat. Aparicio, Anochecer en el pueblo, Ns. Jovs., 135, 1955, 8); «No es difícil hacer una entrevista a Palop, pero cree el novichero armante de estas notas que el humorista enguerino le tomará el pelo» (Ns. Jovs., 147-59, 1957, 12): «PEPI. Pare, usté dice que soy novichera, pero desde q'hamos entráu estoy despepitá por saber una cosa ...» (Los Pastoretes d'Engra, Ns. Jovs., 66, 1949, 112)

Este vocablo procede del val. novitxer. Entre los diccionarios valencianos del s. XIX sólo el de Martí Gadea (València, 1891) recoge esta voz y su derivado novitxeria (grafia novig-) con la definición respectivamente: 'amigo de propalar chismes de vecindad' y 'chisme o enredo de vecindat'. Por lo demás, Martí Gadea usó novitxer en su obra folklórica Tipos o modismes de la terra del Gè (València, 1906): «Els novigers de Manisses: s'aplica el sobrenom ... perquè son molt curiosos per a anar a vore prou sovint lo que passa per València» (II, 156); otro ejemplo también se refiere a los novitxers de Manisses (p. 26), y en la p. 276 leemos: "Alguna criada novigera i amiga de eixir a la porta del carrer».

Joaquim Martí Gadea era de la comarca de Alcoy, y de allí deducimos que novitxer y novitxeria debieron de tener uso especialmente en valenciano meridional. Con este motivo, novitxer 'amic de porta noves, xafarder' está recogido por el Dicc. Norm. Val. Así y todo, según nos informa el filólogo Eugeni S. Reig, de Alcoy, novitxer y novitxeria no se oyen en esa ciudad, y, en su opinión, hoy están desconocidos en valenciano. Así pues, todo indica que estamos en presencia de dos vocablos valencianos, hoy día en desuso, que han tenido continuación en nuestra zona

REVISTA VALENCIANA DE FILOLOGIA / I (20I7) p. I83-I99 JOSEPH GULSOY

Aportacions del 'Vocabulario de Enguera y la Canal de Navarrés' / I 94 
con gran vitalidad y aun han creado nuevos brotes como novicheo y novichear.

El DCVB documenta novitxer 'amic de saber i portar noves' en el Diccionario Catalán-Latino de P. Torra (Barcelona, 1647) y en la mencionada obra de Martí Gadea. Lo da como voz propia del valenciano y, por lo demás, lo considera una forma variante de novatxer. Este último definido 'portta noves' aparece en los diccionarios catalanes del s. XIx: Belvitges (de 1805) y Labernia (de 1840); el DCVB cita un ejemplo de novatxer de la obra de E. Vilanova (1840-1905), y parece tener algún uso hoy día a juzgar por su inclusión en el Diccionari de la llengua catalana del Institut d'Estudis Catalans.

Todo indica que novatxer también debió de tener uso en el dominio valenciano al lado de novitxer. Brauli Montoya recoge novatxer en el Fondó de les Neus (comarca del Vinalopó Mitjà) y novachero en el pueblo de Elda, de habla castellana (La interferencia lingüística al sud valencià, Valencia, Generalitat Valenciana, 1989, p. 108)

El origen de novitxer es problemático. En el DECat me había ocupado de esta cuestión brevemente (V,073ª 59 ss.). Allí traté de derivarlo de novici 'principiante en un oficio', que quiere saber y enterarse de todo; por lo demás, había visto un contacto entre novici y batxiller 'individu inclinat a tafanejar', o sea 'porta noves'. Ahora puedo añadir un dato importante a favor de esta tesis. Nuestros datos de Enguera incluyen novich (m.) en el mismo sentido de novichero 'curioso' (supra). Esto nos prueba la presencia de novitx (m.) 'curioso' en el valenciano. Ahora bien, con este antecedente sería lógico derivar novitxer de novici. Quisiera agregar que esta explicación es provisional.

(b) Palitròc (Anna), pronun. palitràc (Ebg), palitroque (Chella, Quesa), palistroque (Bolb). m. Palitroque, palo pequeño mal formado o deformado // 2. Ponce Palop, El habla de Chella, hace notar: palitroque es «el tallo de la planta una vez desprovisto de todas las hojas, en especial ... se aplica a los tallos secos de la planta del tabaco, [que] son como palos; en septiembre se realiza la recogida del tabaco ... Tras la subida con las garruchas a las cambras (= el piso alto de la casa) para su oreado y secado las hojas se desprenden de los tallos y éstos pasan a la categoría de "palitroques" , y añade: "Como se tiraban en los

REVISTA VALENCIANA DE FILOLOGIA / I (20I7) p. I83-I99 JOSEPH GULSOY Aportacions del 'Vocabulario de Enguera y la Canal de Navarrés' / I95 
campos, los "muñacos" los aprovechábamos para hacernos cabañas y jugar con ellos", y cita este ejemplo de su uso en la llamada de un niño a un grupo de ellos: "Veníse usotros y asina arreplegamos aquella garberá (= montón) de palitroques y nos hasemos una caseta con ellos» (p. 103); "YALA. Yo soy bien educá ... pero hay cosas que no se puén aguantar y a algunas cuchapanderas como tú, ¡a palitroques las tengo que baldar!» (J. A. Palop Ibáñez, Las muletas de San Antón, Autores del s. XXI, p. 39) // 3. Un palo de madera de unas $20 \mathrm{~cm}$ con un gancho que sirve para apretar la cuerda que pasa alrededor de la pancha de la caballería y la carga [de garbas, etc.); garabato (Bolb, Quesa)

Cf. Palitròc (Anna, Eng) proviene del val. palitroc y pali(s)troque (Chella, Bolb, Quesa) del cast. palitroque ‘palo pequeño, tosco o mal formado' (Dicc. Acad.); la forma val. palitroc, a su vez, también proviene del cast. palitroque. Esta voz primera se documenta en la forma de palitroque en el Diccionario de Autoridades de la Real Academia (1726-1739): «Palo pequeño, mal formado y tosco. Úsase regularmente en plural, y se dice cuando hay muchos unidos y trabados unos con otros"; notemos: palitroque se deriva de palito: palitoque > palitroque (DCECH IV, 356b41)

En valenciano palitroc aparece en Escrig (1851): «Palitròc. Palitoque, palitroque o palo pequeño, tosco y mal formado», definición que va de acuerdo con la del Dicc. Aut.; luego aparece en el diccionario de Martí Gadea (1891) con la misma definición. No lo recogen Pastor Ferrer y el DNV y hoy es desconocido en valenciano en general. Pero Eugeni S. Reig, gran autoridad del valenciano actual, ha podido cerciorar que es voz bastante usual en Beneixama (Alcoià) y que fue usado por Francesc Gascó en su obra Rondalles de la Vall d'Albaida i l'Alcoià (València, 1999). El CIVAL (Corpus Informatitzat del Valencià de la AVL) trae dos ejemplos de esta obra y uno de otra: "L'amic va agafar un palitroc i va fer així: “Zac, zog” en mig de la coca, i la va fer partir en quatre parts», y luego «amb el palitroc va rebolicar la coca amb la cendra» (p. 65); y de otra rondalla del mismo autor: «[ells] van pensar de gastar-li un malifeta al pobre home. Van agafar la velleta i la van posar dreta damunt les arganelles, lligat el cos d'un palitroc perquè no caiguera, i van ahuixar la somera"; cf. nuestra acep. \# 3: 'un palo de madera de unos $20 \mathrm{~cm}$ con un gancho que sirve para sujetar la carga sobre la caballería».

REVISTA VALENCIANA DE FILOLOGIA / I (20I7) p. I83-I99 JOSEPH GULSOY

Aportacions del 'Vocabulario de Enguera y la Canal de Navarrés' / I 96 
(i) Perpenta: ni -. Hablando de tiempo: calma absoluta, que no corre ni gota de aire (Eng): «Antes de dormir [el serrano] se asomará a la puerta y oteará el tiempo y el campo: si hace buena noche, tranquila y apacible, dirá en alta voz que ni perpenta; si la noche es nubladita y un poco chispona dirá: Mañana, blandura, y con perpenta o con blandura, sereno o lloviendo» (M. Ciges, La vivienda rural, Eng., 1965, 130); «La noche se presentó calmosa, cálida ... no hacía ni perpenta, y las acacias ... ni se movían» (J. Ciges, $\mathrm{Ha}$ pasado un ángel, Eng., 1975, 77) // ni perpenta: ni una gota: «MANUEL. ¿De qué es, de vino o de ausenta / la bufa que traes? / CREVILLENT. No cal; / no ha bebido ni perpenta» (Granero-Ciges, El tintero de la Ayala, p. 103)

Se oye en el pueblo de Villapalacios (Albacete): ni perpenta 'cuando no corre ni gota de aire' (citamos del 77 Lexicario paloteño de E. Quijano Resta, ed. 2003 de internet; y s.v. carasol leemos: «Lugar donde da el sol (cuando sale, claro) muy apreciada por las abuelitas en invierno. Si te pones de noche o nublo, no pillas ni perpenta (ni gota de sol)».

No se encuentra perpenta en fuentes valencianas; tampoco aparece en el Dicc. Acad., pero todo hace el efecto que es vocablo de base castellana, y propio de la zona de La Mancha. En el ej. citado de M. Ciges, «mañana con perpenta" significa 'mañana con aire, con lluvia' (= 'tiempo con precipitación, con movimiento de aire'), y esto sugiere que perpenta sería una voz de base expresiva, formada de la sílaba $p ə r$, $p ə r$, sonido que produce el aire en movimiento en los árboles, en el ambiente. Interesa, con este motivo, el pasaje citado de J. Ciges: «no hacía ni perpenta y las hojas de las acacias ni se movían».

(j) Pliego: llevar a -. Llegar a cumplir un deseo (Eng): «Pepico ha conseguido llevar a pliego su ilusión: terminar de obrar la casa y poner almorlás en el techo» (Mat. Aparicio) // intr. Llegar a pliego: llegar a buen término o buen estado: "No creo que esa relación llegue a pliego", "La Doloretes ha tenido un chiquet antes de tiempo. Es tan poca cosa que no sé si llegará a pliego» (Mat. Aparicio, Palabras enguerinas, II, p. 121)

Cf. Todo indica que enguerino llegar a pliego / llevar a pliego en los sentidos indicados es la castellanización de las locuciones catalanas arribar a aplec

REVISTA VALENCIANA DE FILOLOGIA / I (20I7) p. I83-I99 JOSEPH GULSOY Aportacions del 'Vocabulario de Enguera y la Canal de Navarrés' / I97 
/ plec 'llegar a buen término' y portar a aplec / plec 'llevar a buen término o a buen estado'. Esperaríamos su presencia en valenciano, pero no aparecen en fuentes valencianas y hoy no tienen uso en la lengua hablada según el sondeo de Eugeni S. Reig. Por otra parte, tienen uso hoy día en Mallorca según hace constar el DCVB s.v. aplec y plec 2. Ilustra su sentido con este ejemplo en una canción popular mallorquina: "Cada glop d'aigo que bec / se nua a sa gargamella, / perque s'amor ja n'és vella / i no és arribada a aplec» (Cada sorbo de agua que bebo / se me agarra a la garganta, / porque el amor ya es de mucho tiempo / y no se llega a buen término). El DCVB cita, además, un ejemplo del siglo Xv de un poema incluido en el Cançoner de Masdovelles: «Si us platz, a bon plech / a mi portats». Es evidente que la expresión tenía buena antigüedad en catalán. Suponemos que tenía gran uso también en valenciano en el pasado. No podemos pensar que la expresión viniera a nuestra zona del mallorquino.

El DCVB s.v. aplec relaciona la expresión arribar a aplec 'assolir l'estat que pertoca' con el sentido 'collita, recolecció' de aplec / plec, que refleja el sentido 'recollir' del verbo aplegar / plegar, del cual es el derivado aplec / plec. Luego, s.v. plec relaciona arribar o portar a plec de bé o a bon plec 'arribar a bona fi' con el sentido de la 'reunió de gent', 'reunió de ramats en la muntanya'; sabido es que 'reunir en general' es uno de los sentidos principales de aplegar / plegar.

Ahora bien, la documentación señala que plegar había llegado al catalán también en el sentido de 'arribar' y había tenido gran uso especialmente en valenciano. El DCVB trae ejemplos de siguientes obras valencianas del s. xv: Curial e Güelfa, Tirant lo Blanch, Spill de Jaume Roig, Lo somni de Johan Johan de J. Gassull. Notemos que la forma originaria aplegar en el senido de 'arribar' tiene uso en valenciano actual (Ferrer Pastor, Dicc. gen., DNV), y, de hecho, también en nuestra zona: se oye en Enguera. Teniendo todo esto en cuenta no vacilamos en suponer en valenciano antiguo la presencia de aplec/plec 'término, fin', 'cumplimiento': la base de las locuciones arribar o portar a aplec/plec. Es bien sabido que el cast. llegar es de la misma base que el cat. plegar (PLICARE).

REVISTA VALENCIANA DE FILOLOGIA / I (20I7) p. I83-I99 JOSEPH GULSOY

Aportacions del 'Vocabulario de Enguera y la Canal de Navarrés' / I 98 